\title{
Domesticated horses differ in their behavioural and physiological responses to isolated and group housing.
}

\author{
Kelly Yarnella*, Carol Halla, Chris Royle ${ }^{a}$ Susan L Walker ${ }^{\mathrm{b}}$ \\ aNottingham Trent University, Brackenhurst campus, Southwell, Nottingham, United Kingdom, NG25 0QF. \\ *Kelly.yarnell@ntu.ac.uk \\ ${ }^{\mathrm{b}}$ North of England Zoological Society, Chester Zoo, Caughall Road, Upton-by-Chester, United Kingdom, CH2 \\ $1 \mathrm{LH}$. \\ *Corresponding author:
}

\section{Abstract}

The predominant housing system used for domestic horses is individual stabling however, housing that limits social interaction and requires the horse to live in semi-isolation has been reported to be a concern for equine welfare. The aim of the current study was to compare behavioural and physiological responses of domestic horses in different types of housing design that provided varying levels of social contact. Horses $(n=16)$ were divided equally into four groups and exposed to each of four housing treatments for a period of five days per treatment in a randomized block design. The four housing treatments used were single housed no physical contact (SHNC), single housed semi contact (SHSC), paired housed full contact (PHFC) and group housed full contact (GHFC). During each housing treatment, adrenal activity was recorded using non-invasive faecal corticosterone metabolite analysis (fGC). Thermal images of the eye were captured and eye temperature assessed as a non-invasive measure of the stress response. Behavioural analysis of time budget was carried out and an ease of handling score was assigned to each horse in each treatment using video footage. SHNC horses had significantly higher $(p=0.01)$ concentrations of fGC and were significantly ( $p=0.003)$ more difficult to handle compared to the other housing types. GHFC horses, although not significantly different, had numerically lower concentrations of fGC and were more compliant to handling when compared to all other housing treatments. Eye temperature was significantly $(p=0.0001)$ lower in the group housed treatment when compared to all other treatments. These results indicate that based on physiological and behavioural measures incorporating social contact into the housing design of domestic horses could improve the standard of domestic equine welfare. 
Keywords; equine; behaviour; corticosterone; housing.

\subsection{Introduction}

The predominant housing system used in domestic horses is individual stabling in box stalls that measure around $9-13 \mathrm{~m}^{2}$ (Rivera et al. 2002) and horses are often confined in these stalls for large proportions of the day. This type of management style is used for several reasons, including injury prevention and convenience for the owner (Goodwin 1999). To the human eye the stable appears safe and inviting and is based on an anthropomorphic belief of what the horse finds comfortable (Jørgensen et al. 2009). However, for a social animal that spends most of its time in close contact with con-specifics (Christensen et al. 2002), the isolation due to single housing could potentially activate the stress response. While this immediate physiological response can be considered adaptive, enabling horses to escape from danger, evidence suggests that stress related disease may be the result of repetitive or continuous activation of a system that has evolved to respond to acute emergencies (Sapolsky et al. 2000).

In their natural habitat horses form harem bands that are typically comprised of mares and their foals, yearlings and one stallion (Rivera et al. 2002) and these cohesive bands can roam areas of land up to $78 \mathrm{~km}^{2}$ (Green and Green, 1977). In contrast, domestic horses are kept in a variety of housing systems which offer differing levels of physical freedom, social opportunities and ability to forage which some horses find stressful. Changes in time budget (Benhajali et al. 2007) and manageability of horses (Rivera et al. 2002) have been found to be associated with housing design which has implications on both equine wellbeing and the safety of horse and handler.

The behaviour of horses in their natural state is often used to assess the welfare of domestic horses (Veasey et al. 1996). The assumption is that a healthy free ranging horse is likely to have adequate welfare as it has the opportunity to socialise, forage and display natural behaviour and a captive horse that is restricted in its expression of certain behavioural patterns may be a welfare concern. It is worth noting that a wild environment does not always offer optimum welfare and domestication has removed many dangers 
faced by wild horses including predation, hunger, thirst and some diseases. A more practical approach may be to use studies of wild or feral horses to identify those behaviours that are most important. This knowledge could then be used to modify management practices and housing design in order to allow natural behaviour to be performed (Winskill et al. 1995).

A characteristic for the healthy unimpaired animal is repetition of daily routine (Berger et al. 2003) and studies report more or less identical time patterns of behaviour from day to day in stress free horses (Mayes and Duncan, 1986). Allowing domestic horses the opportunity to display natural behaviour and managing horses in a way that reflects their natural habitat has resulted in horses displaying time budgets similar to those of wild horses. Paddock housed weanlings have been reported to display time budgets similar to feral horses and show strong motivation to be near con-specifics when compared to stalled weanlings, who spend significantly more time engaged in stereotypical behaviour (Heleski el at. 2002). Horses managed in ways that allow natural behaviour to be expressed have also shown improvements in response to training. Group housed horses took less time to complete a training procedure than horses singly housed in stalls. In addition, group housed horses showed less agonistic behaviour toward the trainer (biting and kicking) than singly housed horses (Rivera et al. 2002).

Stereotypic behaviour in the horse may be associated with stress caused by an inadequate environment including housing type (McBride and Cuddelford, 2001). Stable design allowing visual contact between horses has been associated with a reduced risk of stereotypic behaviour (McGreevy et al. 1995) and increasing visual and tactile contact between horses significantly reduces weaving and nodding when compared to conventional stables where horses have no contact with one another (Cooper et al. 2000). In stabled horses the provision of an enrichment device that requires work to extract food with the aim of extending foraging time (Equiball) has also been shown to reduce stereotypic behaviour (Henderson and Waran, 2001). 
It seems that housing horses in a way that reflects their natural habitat and allows social interaction has benefits for equine wellbeing. Existing studies in this area have focussed only on first time stabling in young or recently weaned horses (Heleski et al. 2002; Søndergaard and Ladewig, 2004; Visser et al. 2008). It is therefore important that current housing types are assessed objectively to evaluate their impact on adult equine physiology and behaviour. It is also important to assess new housing designs that allow natural behaviour to be displayed. This will allow adaptations to housing design to be made in order to reduce the impact of captivity.

Measuring glucocorticoids as an indicator of adrenal activity can increase understanding of the causes of poor welfare (Clark et al. 2011) and provides a more objective measure than behaviour alone. Monitoring adrenal activity through blood sampling can induce a stress response and potentially confound results, so non-invasive sampling methods are often preferred (Cooke and O'Connor, 2010). Faecal corticosterone assessment avoids sampling stress (Keay et al. 2006) and this form of analyses is better suited to long term welfare profiling (Touma and Palme 2005).

Infrared thermography (IRT) has recently been shown to provide an objective, noninvasive measure of the physiological response to an aversive situation in horses (Yarnell et al. 2013) through assessment of eye temperature change that correlated with increased salivary cortisol (an accepted measure of the stress response). Therefore, IRT was utilised during this study as an additional physiological measure.

The aim of this study was to assess the impact of housing design that provided differing levels of social contact upon 1) time budget 2) adrenal activity using non-invasive faecal corticosterone metabolite analysis (fGC) 3 ) eye temperature and 4) ease of handling in domestic horses. 


\subsection{Materials and methods}

\subsubsection{Animals and Husbandry}

Horses of mixed breed $(n=16)$ aged 6 to 21 years (mean age 15 years \pm 3 ) consisting of eight geldings and eight mares, housed at Nottingham Trent University Equestrian Centre, Brackenhurst campus, Nottingham, United Kingdom were used in this study. The horses were ridden in the University riding school for a maximum of two hours per day during term time. However, this study was conducted over the summer outside of academic term time therefore, horses were not being ridden. One horse had been known to display stereotypical behaviour (cribbing) in the year before the study began. No other horse that took part in the study was known to display stereotypical behaviour. The study was given ethical approval by the School of Animal, Rural and Environmental Sciences at Nottingham Trent University.

\subsubsection{Experiment Design}

The study was conducted over one month in August and each week, horses were exposed to one of four housing treatments ( $n=4$ horse/treatment according to gender) in a randomized block design for a period of five days. Following this the horses were turned out into grass paddocks in their experimental groups for two days before exposure to the next housing treatment. The four housing treatments were single housed no physical contact (SHNC), single housed semi contact (SHSC), paired housed full contact (PHFC) and group housed full contact (GHFC). See table 1 for details of each housing type. 
Table 1 The four housing treatments used in the study with differing levels of social and physical contact.

\section{Housing treatment Description}

\begin{tabular}{|c|c|}
\hline Group housing full contact (GHFC) & $\begin{array}{l}\text { Horses were turned out in their experimental } \\
\text { group of four into a paddock which had been } \\
\text { grazed bare prior to the study commencing. The } \\
\text { horses had full physical contact with all other } \\
\text { members of the group and had visual and } \\
\text { auditory contact with horses in nearby } \\
\text { paddocks. }\end{array}$ \\
\hline Paired housing full contact (PHFC) & $\begin{array}{l}\text { Horses were housed in pairs in a barn measuring } \\
10 \times 9 \text { metres. The barn lies adjacent to indoor } \\
\text { single box stables which allowed the study } \\
\text { horses visual and auditory contact with the } \\
\text { horses stabled in them. In addition there were } \\
\text { two horses housed in the neighbouring barn } \\
\text { (from the same experimental group of four) } \\
\text { which allowed visual and auditory contact } \\
\text { through a wire partition separating the two } \\
\text { enclosures. Each pair of horses had full physical } \\
\text { contact with one another. }\end{array}$ \\
\hline Single housing, semi contact (SHSC) & $\begin{array}{l}\text { Horses were individually housed in box stables } \\
\text { measuring } 3 \times 3.6 \text { metres with a solid wall to } \\
\text { ceiling height at the rear. The front, sides and } \\
\text { integrated sliding door of the stable measured a } \\
\text { total height of } 2.5 \text { metres with solid walls to } 1.2 \\
\text { metres high and vertical metal bars spaced at } \\
5 \mathrm{~cm} \text { apart for the remainder of the height. } \\
\text { Visual, auditory and tactile communication with } \\
\text { the neighbouring horse at either side was } \\
\text { possible through the bars and the horses were } \\
\text { also able to see their companions stabled } \\
\text { opposite in the same housing treatment. }\end{array}$ \\
\hline Single housed no contact (SHNC) & $\begin{array}{l}\text { Horses were housed in box stables measuring } 3 \\
\text { by } 3.6 \text { with } 2.5 \text { metre high solid brick walls to } \\
\text { the rear and side. No contact with other horses } \\
\text { was possible. }\end{array}$ \\
\hline
\end{tabular}

This table provides details of each of the four housing treatments used in this study which were group housed full contact in a paddock (GHFC), Paired housed full contact in a barn (PHFC), Single housed semi contact in stables with bars (SHSC) and Single housed no contact in traditional box stables (SHNC). Horses were rotated in groups of four through each of the treatments for a period of five days per treatment. 
For each treatment horses were brought from their paddocks to the relevant housing at $1600 \mathrm{~h}$ and remained there until $1600 \mathrm{~h}$ the following day. This was to ensure that the first faecal samples collected were reflective of the change in environment from the paddock to the specific housing type. The horses were then walked back to their paddock by the same handler and turned out in their experimental group overnight until 0800h. This process was repeated with horses being brought into the experimental housing at $0800 \mathrm{~h}$ and turned out at $1600 \mathrm{~h}$ for the remainder of the week to simulate normal husbandry procedures in the equine species. Whilst turned out horses had full contact with other members of their experimental group in addition to visual and auditory contact with horses in the other experimental groups in neighbouring paddocks.

\subsubsection{Faecal collection and analysis}

A subset of samples were collected once per day on Day 1,2 and 3 of the treatment from $\mathrm{n}=8$ horses ( $\mathrm{n}=2$ horses within each treatment) as soon as possible and within one hour after defecation and stored at $-20^{\circ} \mathrm{C}$ until hormone analysis. All samples were collected after $1200 \mathrm{~h}$ on the first full day of stabling meaning that the first sample on day one was collected at least twenty hours after the horse was introduced to the housing design. Samples from day 1, 2 and 3 (total of twenty four samples per treatment) were assessed with fGC levels reflective of the past eighteen hours due to rate of passage of digesta (Uden et al. 1982). The same horses were used for faecal analysis throughout the study.

Hormones were extracted from faecal samples following thawing and manual homogenization using a wet-weight shaking extraction adapted from Walker et al. (2002). In brief, 0.5 grams of faecal material was combined with $90 \%$ methanol, shaken overnight at room temperature and centrifuged for 20 minutes at $598 \mathrm{~g}$. The methanol fraction was decanted and evaporated to dryness. Faecal extracts were re-suspended in $1 \mathrm{ml}$ methanol and stored at $-20^{\circ} \mathrm{C}$ until analysis.

The enzyme linked-immunoassay (EIA) utilized an antibody (polyclonal corticosterone CJM006 antiserum supplied by CJ Munro, University of California, Davis, CA), horseradish 
peroxidase conjugated label [corticosterone; prepared according to Munro and Stabenfeldt (1984)] and standards (corticosterone; Sigma-Aldrich, UK). The modified assay procedures were as follows for the corticosterone EIA: i) antiserum was diluted at $1: 15,000$ in coating buffer $(0.05 \mathrm{M}$ NaHCO3, $\mathrm{pH} 9.6)$ loaded $50 \mu \mathrm{l} /$ well on a 96 -well NuncImmuno Maxisorp (Thermo-Fisher Scientific) microtiter plate, covered with a plate sealer and left overnight at $4^{\circ} \mathrm{C}$ ii) plates were washed five times $(0.15 \mathrm{M} \mathrm{NaCl}, 0.05 \%$ Tween 20$)$ iii) standards (corticosterone, $3.9-1000 \mathrm{pg} /$ well) or samples diluted 1:20 in EIA buffer ( $0.1 \mathrm{M} \mathrm{NaPO} 4,0.149 \mathrm{M} \mathrm{NaCl}, 0.1 \%$ bovine serum albumin, $\mathrm{pH} 7.0$ ) were loaded $50 \mu \mathrm{l} /$ well; and $\mathrm{iii)}$ the horseradish peroxidase conjugate was diluted in EIA buffer to 1:70,000 and added $50 \mu \mathrm{l} /$ well. Following incubation in the dark for 2 hours RT, plates were washed 5 times and incubated with $100 \mathrm{ul} /$ well of RT substrate [0.4mM 2,2'-azino-di-(3ethylbenzthiazoline sulfonic acid) diammonium salt, $1.6 \mathrm{mM} \mathrm{H} 2 \mathrm{O} 2,0.05 \mathrm{M}$ citrate, $\mathrm{pH} 4.0$ ) and left to develop at RT in the dark and measured at $405 \mathrm{~nm}$ at optical density 0.8 to 1.0 . The corticosterone antiserum CJM006 cross reactives are published elsewhere (Watson et al. 2013) and the intra- and inter-assay coefficients of variation for the corticosterone assay were 7.52 and $6.33 \%(\mathrm{C} 1$ and $\mathrm{C} 2)$ and 8.66 and $10.47 \%(\mathrm{C} 1$ and $\mathrm{C} 2$ ) respectively.

The corticosterone assay was validated for measuring corticosterone metabolites in female and male domestic horse faeces by parallelism and accuracy check. Serial dilutions of domestic horse faecal extract yielded a displacement curve parallel to the standard curve (female: sample \% binding $=29.989+0.7198$ (standard \% binding), R2 0.95594, F1, 7 $=151.865, \mathrm{p}<0.001 ;$ male sample $\%$ binding $=25.349+0.729$ (standard \% binding), $\mathrm{R} 20.9545, \mathrm{~F} 1,7=146.710, \mathrm{p}<0.001)$. There was no evidence of matrix interference, as addition of diluted faecal extract to corticosterone standards did not alter the amount expected (female: Observed $=0.9122+0.0011$ (Expected), $\mathrm{R} 2=0.9972, \mathrm{~F} 1,7=$ 2432.65, $\mathrm{p}<0.001 ;$ male: Observed $=1.302+1.017$ (Expected), $\mathrm{R} 2=0.9972, \mathrm{~F} 1,7=$ $1287.128, \mathrm{p}<0.001)$.

The assay was biologically validated by demonstrating a significant rise in faecal glucocorticoid metabolite concentrations between the social housing type and the isolated 
housing type (Students paired $t$ test; $t=2.81$, d.f. $=21, \mathrm{p}=0.01$ ).

\subsubsection{Infrared Thermography and temperature collection}

Thermal images of the left and right lateral aspect of the head were captured three times per day at $0830 \mathrm{~h}, 1200 \mathrm{~h}$ and $1530 \mathrm{~h}$ for each horse using a Mobir ${ }^{\circledR}$ GuidIR M4 thermal camera. The camera has a thermal sensitivity of $\leq 0.1^{\circ} \mathrm{C}$ and can detect temperature at a range of $-20^{\circ} \mathrm{C}$ to $250^{\circ} \mathrm{C}$. Thermal images were uploaded to $\mathrm{Mobir}^{\circledR}$ thermal analysis software and the human user's task was to use a mouse interface to fit a polygon over the area to be assessed. The software then scanned this region in order to find the peak temperature. Eye temperature analysis recorded maximum temperature within the medial posterior palpebral border of the lower eyelid and the lacrimal caruncle as in Yarnell et al. (2013). A mean temperature was then calculated from left and right eye for each time point. Ambient temperature was recorded for the duration of the study and each horse had its rectal temperature taken three times daily using a digital thermometer (Boots, UK) at $0830 \mathrm{~h}, 1200 \mathrm{~h}$ and $1530 \mathrm{~h}$ by the same handler in order to investigate any relationship between eye temperature measured using IRT and rectal temperature. In order for rectal temperature to be measured and the thermal image to be captured horses were required to wear a head collar and to be loosely restrained during each sampling time point.

\subsubsection{Behavioural data collection}

Behavioural observations were carried out on Day 4 of each housing treatment which was the last full day horses spent in the housing design having being housed there for three full days previously. Horses $(n=10)$ were observed continuously for seven hours (minimum $\mathrm{n}=2$ horses within each treatment) using a remote camera system installed in the housing (Anatel catalyst 3560 series, Cisco systems, China). An ethogram (Table 2) adapted from Cooper et al. (2000) and Heleski et al. (2002) was used to record the behavioural state of each horse. The percentage of total time spent performing each behavioural state was then calculated. Only behaviours lasting longer than five seconds were recorded. 
Table 2. Ethogram with behavioural definitions used

\begin{tabular}{|l|l|}
\hline $\begin{array}{l}\text { Behavioural } \\
\text { state }\end{array}$ & Definition \\
\hline Standing & $\begin{array}{l}\text { Includes standing alert with eyes fully } \\
\text { open, ears forward, and body position } \\
\text { showing alertness or standing resting, } \\
\text { stood still, one or both ears back, relaxed } \\
\text { neck (lower than when alert) and eyes } \\
\text { fully or partially closed, }\end{array}$ \\
\hline Lying & $\begin{array}{l}\text { Includes Lying sternally, lying stretched } \\
\text { out on their side or rolling }\end{array}$ \\
\hline Active & $\begin{array}{l}\text { Includes walk (four beat gait of forward } \\
\text { movement), trot (two beat diagonal gait of } \\
\text { forward movement) and canter (three beat } \\
\text { gait of forward movement) }\end{array}$ \\
\hline Social & $\begin{array}{l}\text { Includes positive social behaviour } \\
\text { (Interactive behaviour; nuzzling/sniffing } \\
\text { another horse or mutual grooming) and } \\
\text { negative social behaviour (aggressive } \\
\text { behaviour, laid back ears, lowered head } \\
\text { and neck, dominant body position, threat } \\
\text { to kick/bite or actual kick/bite) }\end{array}$ \\
\hline $\begin{array}{l}\text { Ingestion of grass or hay and intake of } \\
\text { water }\end{array}$ \\
\hline This table shows the Ethogram with behavioural definitions
\end{tabular}

This table shows the Ethogram with behavioural definitions used to assess the time budget of horses $(n=10)$ during a seven hour period on the fourth day spent in each housing treatment. Behaviours lasting longer than five seconds were recorded. Ethogram is adapted from Cooper et al. (2000)and Heleski et al. (2002).

\subsubsection{Ease of handling data collection}

During the fourth day of each housing treatment the monitoring of rectal temperature and eye temperature were used as an example of a handling procedure as the horses were required to be fitted with a head collar whilst the measures were taken (eye temperature first). This procedure was captured by the remote camera system and an ease of handling score was calculated. This was done by showing the video footage to twenty one equine science undergraduate students in a random order and using the objective definitions in table 3, a mean ease of handling score for each horse from the three sampling points 
throughout the day was calculated. A mean handling score for each housing treatment was also calculated using all horses $(n=16)$.

Table 3 ease of handling score with scores ranging from 1 (compliant to handling) to 5 (resistant to handling). Evasive movement of head is an elevated head carriage or lateral movement away from the handler.

\begin{tabular}{|c|l|}
\hline Score & Behavioural definition \\
\hline $\mathbf{1}$ & $\begin{array}{l}\text { Sample obtained with no evasive movement of head or steps away from } \\
\text { handler }\end{array}$ \\
\hline $\mathbf{2}$ & $\begin{array}{l}\text { Sample obtained after 1-3 attempts due to evasive movement of head } \\
\text { with no steps away from handler }\end{array}$ \\
\hline $\mathbf{3}$ & $\begin{array}{l}\text { Sample obtained after 3-5 attempts due to evasive movement of head } \\
\text { and/or steps away from handler. }\end{array}$ \\
\hline $\mathbf{4}$ & $\begin{array}{l}\text { Sample obtained after more than five attempts due to evasive } \\
\text { movement of head and/or steps away from handler. }\end{array}$ \\
\hline $\mathbf{5}$ & $\begin{array}{l}\text { Sample obtained after more than five attempts due to evasive } \\
\text { movement of head and steps away from handler }\end{array}$ \\
\hline
\end{tabular}

This table shows the ease of handling score used to assess compliance of the horses $(n=16)$ with scores ranging from 1 (compliant to handling) to 5 (resistant to handling). Evasive movement of head is an elevated head carriage or lateral movement away from the handler. Scores were attributed to each horse during the three handling procedures on the fourth day of each housing treatment

\subsubsection{Data analysis}

All statistical analyses conducted throughout this study were carried out using IBM SPSS Statistics 19. Following a Kolmogorov-Smirnov test fGC data did not vary significantly from the normal distribution. Parallelism data for both male and female horses were similar however, an independent t-test was carried out to investigate any differences in fGC between the two sexes. The effect of housing type on mean faecal corticosterone metabolites $(\mathrm{ng} / \mathrm{g})$ were analysed using a one way repeated measures ANOVA. One horse was removed from the analysis as faecal samples were not collected for all treatments due to the horse not producing faeces on a regular enough basis. The effect of housing treatment on eye temperature was investigated using a one way repeated measures ANOVA in addition to any differences in rectal and ambient temperature between housing treatments. Spearman rank order correlation was utilised to investigate any relationship between mean eye, rectal and ambient temperature overall. 
A Friedmann ANOVA was conducted to test for differences in time budget between housing treatments and a one way repeated measures ANOVA was conducted to examine any difference in ease of handling between housing treatments. All post hoc comparisons were done using a Bonferroni test.

\subsection{Results}

\subsubsection{Faecal Corticosterone metabolite}

There was no significant difference in cortiscosterone levels between male horses $(M=$ $37.7, S D=14.1)$ and female horses $(M=33.8, S D=12.7 ; t(70)=1.23, p=0.22)$. The level of fGC increased as the level of isolation increased. Single housed no contact (SHNC) horses had significantly higher levels of fGC compared to all other treatments (Wilks Lambda $=0.58, F(3,18)=4.29, \mathrm{p}=0.01$, multivariate partial eta squared $=0.42 ; \mathrm{p} \leq$ 0.02). The level of fGC was higher for all horses on all three sample days during the SHNC treatment when compared to the other treatments. The overall concentrations of fGC for each housing treatment were $31.05( \pm 7.8 \mathrm{ng} / \mathrm{g})$ for the GHFC, $33.69( \pm 10.3 \mathrm{ng} / \mathrm{g})$ for the PHFC, $34.44( \pm 13.6 \mathrm{ng} / \mathrm{g})$ for the SHSC and $40.56( \pm 16.5 \mathrm{ng} / \mathrm{g})$ for the SHNC treatment. Table 4 details fGC concentrations for all horses sampled on each day spent in each housing type. 
Table 4 Mean $( \pm S D)$ faecal corticosterone $(\mathrm{ng} / \mathrm{g}$ ) for each housing treatment for days 1 , 2 and 3 and mean faecal corticosterone $(\mathrm{ng} / \mathrm{g}$ ) for all three days (overall) in each housing treatment.

\section{MEAN ( \pm SD) FAECAL CORTICOSTERONE (ng/g) IN EACH HOUSING TREATMENT}

\begin{tabular}{lllll}
$\begin{array}{l}\text { HOUSING } \\
\text { TREATMENT }\end{array}$ & Day 1 & Day 2 & Day 3 & OVERALL \\
\hline GHFC & $31.73 \pm 10.2$ & $32.18 \pm 8.0$ & $29.22 \pm 5.9$ & $31.05 \pm 7.8$ \\
\hline PHFC & $32.75 \pm 10.0$ & $33.66 \pm 12.9$ & $34.67 \pm 9.3$ & $33.69 \pm 10.3$ \\
\hline SHSC & $35.06 \pm 14.6$ & $35.14 \pm 15.9$ & $33.13 \pm 12.5$ & $34.44 \pm 13.6$ \\
\hline SHNC & $38.16 \pm 17.8$ & $42.00 \pm 16.7$ & $41.52 \pm 17.6$ & $\begin{array}{l}* \\
40.56 \pm 16.5\end{array}$
\end{tabular}

This table shows the mean values for faecal corticosterone $(\mathrm{ng} / \mathrm{g}) \pm$ standard deviation for each of the housing treatments (GHFC, PHFC, SHSC, SHNC) for seven horses during day 1, 2 and 3. Samples were collected at least twenty hours after horses entered the housing treatment. It also shows mean faecal corticosterone $(\mathrm{ng} / \mathrm{g}) \pm$ standard deviation for seven horses for all three days (overall) in each housing treatment. The faecal corticosterone concentration was significantly higher $(*)$ during the single housed no contact treatment. The lowest concentration of faecal corticosterone for all days was found in the group housed full contact treatment.

\subsubsection{Temperature assessment}

\subsubsection{Infrared thermography of the eye}

The highest mean eye temperature was recorded during the PHFC $\left(38.2 \pm 1.2^{\circ} \mathrm{C}\right)$ treatment when compared to the SHSC $\left(38.0 \pm 1.1^{\circ} \mathrm{C}\right)$, SHNC $\left(38.0 \pm 1.3^{\circ} \mathrm{C}\right)$ and GHFC $\left(36.8 \pm 1.5^{\circ} \mathrm{C}\right)$ treatments. There was a significant effect of housing treatment on eye temperature, Wilks Lambda $=0.68, F(3,221)=34.1, \mathrm{p}<0.001$, multivariate partial eta squared $=0.32$. Eye temperature was significantly lower during the GHFC treatment when compared to the other three treatments (Table 5). 
Table 5 Difference $( \pm S E)$ in mean eye and rectal temperature between each of the four housing treatments.

\begin{tabular}{|c|c|c|c|}
\hline $\begin{array}{l}\text { Housing } \\
\text { treatment }\end{array}$ & $\begin{array}{l}\text { Housing } \\
\text { treatment }\end{array}$ & $\begin{array}{c}\text { Difference in } \\
\text { mean eye } \\
\text { temperature } \\
( \pm S E)\end{array}$ & $\begin{array}{c}\text { Difference in } \\
\text { mean rectal } \\
\text { temperature } \\
( \pm S E)\end{array}$ \\
\hline GHFC & $\begin{array}{l}\text { PHFC } \\
\text { SHNC } \\
\text { SHSC }\end{array}$ & $\begin{array}{l}-1.408(0.14)^{*} \\
-\mathbf{1 . 1 1 4}(0.13)^{*} \\
-1.115(0.13)^{*}\end{array}$ & $\begin{array}{l}-1.445(0.09)^{*} \\
-1.151(0.10)^{*} \\
-1.146(0.08)^{*}\end{array}$ \\
\hline PHFC & $\begin{array}{l}\text { GHFC } \\
\text { SHNC } \\
\text { SHSC }\end{array}$ & $\begin{array}{c}1.408(0.14)^{*} \\
0.293(0.12) \\
0.292(\mathbf{0 . 1 1})\end{array}$ & $\begin{array}{r}1.445(0.09)^{*} \\
0.294(0.12) \\
\mathbf{0 . 3 0 0}(0.11)\end{array}$ \\
\hline SHSC & $\begin{array}{l}\text { GHFC } \\
\text { PHFC } \\
\text { SHNC }\end{array}$ & $\begin{array}{r}1.115(0.14)^{*} \\
-0.292(0.11) \\
0.001(0.11)\end{array}$ & $\begin{array}{r}1.151(0.08)^{*} \\
-0.294(0.11) \\
0.006(0.11)\end{array}$ \\
\hline SHNC & $\begin{array}{l}\text { GHFC } \\
\text { PHFC } \\
\text { SHSC }\end{array}$ & $\begin{array}{c}1.114(0.13)^{*} \\
-0.293(0.12) \\
-0.001(0.11)\end{array}$ & $\begin{array}{r}1.151(0.10)^{*} \\
-0.294(0.10) \\
0.006(0.11)\end{array}$ \\
\hline
\end{tabular}

This table details the differences found in mean eye temperature and mean rectal temperature between the four housing treatments which were group housed full contact (GHFC), paired housed full contact (PHFC). Single housed semi contact (SHSC) and single housed no contact (SHNC). Data highlighted in bold indicates a significant difference in eye temperature between housing treatments at the level of $p<0.05$. An $*$ indicates significance at the level of $p<0.001$.

\subsubsection{Rectal temperature}

The highest mean rectal temperature was recorded in the PHFC $\left(38.3 \pm 1.2^{\circ} \mathrm{C}\right)$ treatment when compared to the other three treatments of, $\operatorname{SHSC}\left(38 \pm 1.1^{\circ} \mathrm{C}\right), \operatorname{SHNC}\left(38 \pm 1.3^{\circ} \mathrm{C}\right)$ and GHFC $\left(36.9 \pm 0.5^{\circ} \mathrm{C}\right)$.

There was a significant difference in rectal temperature between housing treatment, Wilks Lambda $=0.38, F(3,220)=118, \mathrm{p}<0.001$, multivariate partial eta squared $=0.62$. (Table 5)

Rectal temperature was significantly lower $(p<0.001)$ during the GHFC treatment when compared to the other three treatments. There was also a significant difference in rectal temperature between the PHFC and SHSC treatments $(p=0.04)$ with the mean rectal temperature in the paired housing being lower than in the SHSC housing. 


\subsubsection{Ambient temperature}

There was a significant difference in ambient temperature between housing treatment, Wilks Lambda $=0.88, F(3,220)=9.8, \mathrm{p}<0.001$, multivariate partial eta squared $=0.12$ with ambient temperature highest in the GHFC treatment. There was a significant difference in ambient temperature between the GHFC housing treatment and all other housing treatments $(p<0.001)$. There were no other significant differences in ambient temperature between any of the other housing treatments.

\subsubsection{Correlation analysis}

Overall there was a strong positive correlation between mean rectal and mean ambient temperature, rho $=0.668, \mathrm{n}=16, \mathrm{p}=0.005$ with high rectal temperatures associated with high ambient temperatures. No correlation was found between mean eye and mean rectal temperature $(p=0.66)$ or mean eye and mean ambient temperature $(p=0.68)$.

\subsubsection{Behavioural assessment}

There was a significant difference in time budget for feeding, standing, active and social behaviours between housing conditions (Table 6). Standing behaviour was significantly reduced in the GHFC treatment. There was also a significant increase in active and social negative behaviour in the group housed full contact and paired housed full contact housing

The horse identified as having displayed stereotypical behaviour (cribbing) prior to commencement of the study displayed this behaviour in the SHNC treatment for a total period of 38.4 minutes during the behavioural observation period of seven hours. This was $9.1 \%$ of the time observed. This particular horse did not display stereotypical behaviour in any of the other treatments during the set observation periods.

All horses had a significantly higher ease of handling score (more difficult to handle) in the single housed no contact (SHNC) treatment compared to the other treatments (Figure 1) (Wilks Lambda $=0.36, F(3,13)=7.63, \mathrm{p}=0.003$, multivariate partial eta squared $=$ $0.63 ; p \leq 0.003)$ 
Table 6 Time budget data for horses $(n=10)$ in each of the four housing treatments

\begin{tabular}{|c|c|c|c|c|c|c|}
\hline & Feed & Standing & Lying & Active & $\begin{array}{c}\text { Social } \\
\text { positive }\end{array}$ & $\begin{array}{c}\text { Social } \\
\text { negative }\end{array}$ \\
\hline SHNC & $\begin{array}{c}0.91 \pm 1.0 \\
A\end{array}$ & $\begin{array}{c}88.52 \pm 7.7 \\
\text { A }\end{array}$ & $\begin{array}{l}2.97 \\
\pm 9.0\end{array}$ & $\begin{array}{c}1.76 \pm 0.5 \\
\mathrm{~A}\end{array}$ & $0.00 \pm 0.0$ & $\begin{array}{c}0.00 \pm 0.0 \\
A\end{array}$ \\
\hline SHSC & $\begin{array}{c}3.65 \pm 4.5 \\
\mathrm{~A}\end{array}$ & $\begin{array}{c}89.84 \pm 10.9 \\
\text { A }\end{array}$ & $\begin{array}{l}2.84 \\
\pm 7.4\end{array}$ & $\begin{array}{c}2.06 \pm 0.7 \\
A\end{array}$ & $\begin{array}{l}0.004 \\
\pm 0.01\end{array}$ & $\begin{array}{c}0.04 \pm 0.1 \\
A\end{array}$ \\
\hline PHFC & $\begin{array}{c}5.86 \pm 7.8 \\
A\end{array}$ & $\begin{array}{c}81.18 \pm 6.6 \\
A\end{array}$ & $\begin{array}{l}3.70 \\
\pm 5.9\end{array}$ & $\begin{array}{c}5.42 \pm 4.2 \\
\text { B }\end{array}$ & $1.39 \pm 1.9$ & $\begin{array}{c}1.56 \pm 2.3 \\
B\end{array}$ \\
\hline GHFC & $\begin{array}{c}34.89 \\
\pm 14.3 \\
\text { B }\end{array}$ & $\begin{array}{c}56.27 \pm 14.4 \\
B\end{array}$ & $\begin{array}{l}0.08 \\
\pm 0.1\end{array}$ & $\begin{array}{c}7.36 \pm 2.7 \\
\text { B }\end{array}$ & $1.34 \pm 1.9$ & $\begin{array}{c}0.02 \pm 0.03 \\
A\end{array}$ \\
\hline
\end{tabular}

This table shows the time budgets of ten study horses (minimum two per group) in each of the four housing treatments which were group housed full contact (GHFC), paired housed full contact (PHFC). Single housed semi contact (SHSC) and single housed no contact (SHNC). Values are mean percentage \pm standard deviation. Within a column means with different letters are significantly different $(p=<0.05)$

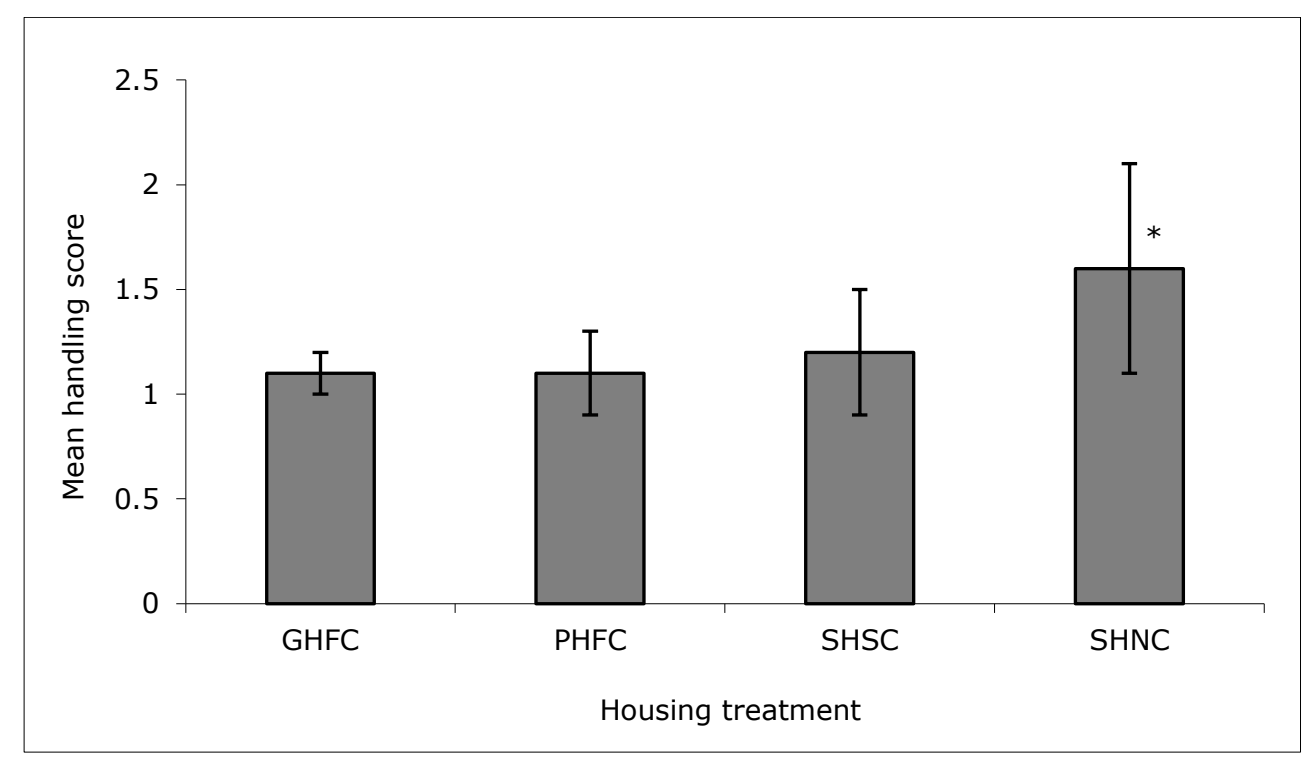

Figure 1 Mean ease of handling score for all horses $(n=16)$ during each housing treatment.

This figure shows the mean ease of handling score for all horses $(n=16)$ during each housing treatment which were group housed full contact (GHFC), paired housed full contact (PHFC). Single housed semi contact (SHSC) and single housed no contact (SHNC). The horses were significantly more difficult to handle $(*)$ during the SHNC treatment when compared to all other treatments. Note that a higher score is related to more difficult to handle. 


\subsection{Discussion}

Housing horses in a way that allowed social interaction resulted in lower levels of fGC in addition to horses that were more compliant to handling. Faecal corticosterone metabolites were significantly higher in the single housed no contact housing treatment in comparison to all other treatments for the three days that samples were taken. This suggests that horses found the restrictive housing aversive or at least less preferable than the housing designs that offered a degree of social contact. The first fGC samples taken were reflective of the past eighteen hours that the horses spent in their housing design due to gut transit time (Uden et al. 1982) and an effect of housing type was apparent at this point with a stronger treatment effect in the most isolated housing. The rise in fGC at the beginning of the week may be a consequence of the horse being removed from the paddock environment and placed into a new housing type however, a treatment effect was still observed between housing types. This suggests that even if the horses simply found the change in environment challenging, placement into more restrictive housing was more challenging that the designs that offered social contact post turnout. The GHFC treatment resulted in numerically lower levels of fGC although this was not significant. Despite varying levels of restriction in the remaining three housing types (GHFC, SHSC, PHFC) no other significant differences in fGC were observed. It may be that the change in level of restriction between the remaining treatments was not severe enough to evoke a significant change in hormone levels. The horses involved in this study are riding school horses that are often stabled and sometimes isolated. This may reduce the perceived aversiveness of semi restrictive housing.

Another potential reason for no significant difference in corticosterone between the remaining three housing treatments is that all horses had been housed in them at some point prior to the study commencing however they had not experienced prolonged periods of complete isolation. Perhaps if horses were exposed to the SHSC treatment having never been housed there previously it may have potentially been more stressful. These findings suggest that total isolation including restriction of visual contact is perceived to be 
significantly more challenging for a domestic horse than restriction of tactile contact alone. If it is not practical to house horses in a group then this study supports the findings of Cooper et al. (2000) by showing that at least allowing visual contact with con-specifics appears to reduce the aversiveness of single housing and is better than total isolation. This has implications for other management practices where the horse is required to be isolated for extended periods of time including transportation and veterinary quarantine.

The adrenal response of the study horses was supported by the handling assessment. Horses were significantly easier to handle when housed as a group compared to the single housed no contact treatment. As the housing treatment became increasingly restricted and isolated for the horses they became increasingly difficult to handle. The ease of handling assessment revealed that horses were significantly more difficult to handle $(p=$ 0.003) in the single housed no contact housing treatment compared to all other treatments. This was the most restrictive and isolated housing and supports the findings of Rivera et al. (2002), who found singly housed horses showed significantly more objectionable behaviour toward their trainer than group housed horses.

To fully understand the impact of housing design it is important to first understand the behaviour of the horse in its natural habitat and then compare that to behaviour in different housing conditions. Where this comparison shows a reduction in the horse's behavioural repertoire or a change in time budget, it is thought to be a sign of reduced welfare (Benhajali et al. 2008).

A significant decrease in standing behaviour was observed in the GHFC treatment compared to the other three housing treatments. The amount of standing behaviour observed (56\%) still exceeds the reported times that horses spend standing in feral herds of $11-21 \%$ by Duncan (1985) and $36.3 \%$ by Boyd et al. (1988) however, Crowell-Davis (1994) reported welsh pony mares resting in a standing position for $50 \%$ of the day during the height of summer. The authors suggest this standing behaviour serves to provide some protection from flies due to the horses standing next to each other and swishing their tails and also to avoid predation by allowing a larger field of vision and eliminating the need to 
rise from a recumbent position prior to flight. With this in mind the present study was conducted in August when fly density was greatest in addition to the group housed treatment resembling an open natural habitat where predation occurs therefore the time spent in standing behaviour of $56 \%$ seems appropriate. Time spent standing was much higher in the other three housing treatments than that of feral horses with a mean standing time of $88.5 \%$ for the SHNC treatment. This is largely due to the physical restriction of movement in these designs resulting in far less active behaviour when compared to the group housed treatments. The time spent active in the PHFC and GHFC treatments are similar to that observed in feral horses (Duncan, 1980: 8-11\%, Duncan, 1985: 5.2-12.7\%, Boyd et al. 1988: 8.5-14.1\%) indicating that the space offered was large enough to increase activity. In the isolated and semi-isolated conditions the horses showed less activity, due to the restricted space allowed. These findings highlight that given the opportunity to move around and engage in active behaviour a horse will utilise the space provided to do so. There was also a significant difference $(p<0.05)$ in feeding behaviour between the GHFC treatment and all other treatments with longer time spent foraging in the GHFC treatment. This is due to the very limited availability of grass in the GHFC treatment. The paddock was grazed bare prior to the study commencing however grazing behaviour was still attempted by the horses on both the ground and surrounding foliage. Similarly to active behaviour this highlights that given the opportunity to forage horses will utilise the time and space to do so.

No significant differences were seen in positive social interaction and very little mutual grooming was observed. This may be due to continually changing the social environment that the horses were exposed to and the short period spent within each housing treatment. Mutual grooming has a social function in the equine species, which results in reduction of tension within a group and offers an intrinsic reward (Feh and de Mazières, 1993). Therefore, more mutual grooming may have been noted in a longer term study that allowed the horses to spend an increased period of time together within one housing treatment. Synchronisation and preferred associates were not measured, however the 
horses were observed to show high levels of synchrony when in group housing conditions. In the group housing conditions the horses were seen to rest frequently next to a particular individual, indicating preferred associates. In the semi-isolated condition the horses were observed resting next to the horse in the adjoining stable, highlighting the importance of careful consideration when grouping and stabling horses. Although the level of social interaction measured in this study was low, more subtle interactions may have occurred, including synchrony and preferred associates.

A significant increase in negative social interaction was seen in the PHFC condition. The social interaction observed was play behaviour and agonistic in nature and in the gelding groups consisted predominantly of threats. Play and agonistic behaviour is a predominant part of the male horse's behavioural repertoire that has adaptive functions including: increased fitness and stamina, skill development, environmental investigation, bond formation and preparation of harems (McDonnell and Poulin, 2002). The demonstration of play behaviour is thought to be an indicator of good welfare (Christensen et al. 2002). Agonistic behaviour in feral mares is used to form dominance hierarchies and once hierarchy is established, agonistic behaviour declines (Heiter, et al. 2006). The mares in this study were being moved through housing conditions that changed the number of horses grouped together potentially disturbing any established hierarchy. It would be interesting to investigate whether housing horses in pairs for longer periods of time to allow maintenance of stable hierarchy would result in a reduced incidence of negative social behaviours.

One study horse known to perform stereotypical behaviour prior to the study commencing displayed this behaviour (cribbing) during the SHNC treatment. This particular horse cribbed during the observation period in the most isolated treatment but not during any of the other treatments. The horse was housed in the SHSC treatment prior to the study where it had been observed to perform stereotypical behaviour. As stereotypical behaviour is potentially indicative of an attempt to cope with an inadequate environment (Mason, 1991 ) it is reasonable to assume that increasing the level of isolation would result in 
stereotypical behaviour being displayed. Interestingly this horse did not crib when housed in its usual housing design during the study. This may have been due to the novelty of being moved through a range of housing treatments or it may be that the evening and weekend turnout provided during the study was sufficient to prevent stereotypical behaviour in the housing treatments that offered some form of contact with con-specifics in comparison with term time stabling when this horse did not receive turnout. This horse was observed for a whole day (seven hours) in each housing treatment and spent thirty minutes of this time engaged in cribbing behaviour in the SHNC treatment which is a relatively small amount of time. These findings do however support the suggestion that increasing access to con-specifics and providing opportunity to display natural behaviour reduces stereotypical behaviour which is a sign of improved wellbeing (McGreevy et al. 1995; Cooper, et al. 2000).

Thermal assessment revealed that mean eye temperature was lowest during the GHFC treatment, despite ambient temperature (likely due to solar radiation) being the highest. Existing work has utilised eye temperature measured using infra-red thermography as an assessment of the short term stress response (Nakayama et al. 2004) and found correlations between glucocorticoid concentration and heart rate (Stewart et al. 2008) with increased eye temperature during aversive situations. The physiological reasoning behind this change is likely to be connected to the sympathetic nervous system response to facilitate flight (Yarnell et al. 2013) and as such it was thought that it may not be an appropriate measure to assess more long term welfare. However, eye temperature was significantly lower in the GHFC treatment compared to all other housing treatments. This could suggest a physiological stress response resulting in higher eye temperatures during the more restrictive treatments. Eye temperature was highest during the PHFC treatment. This may be a reflection upon the higher incidence of negative social behaviour in this treatment which is perhaps due to artificial pairing of horses that had not previously been housed together. The findings of eye temperature measurement during this study support the findings of the fGC and behavioural assessment. Further investigation into eye 
temperature assessment using IRT as an evaluation of long term welfare, with careful monitoring of environmental temperature is warranted.

The alterations in ease of handling, time budget and faecal corticosterone observed during the study appear to be due to the increased opportunity to display natural behaviour in addition to increased contact with con-specifics. The group housed treatment allowed horses to satisfy their roaming needs in addition to providing contact with other horses. The PHFC and SHSC treatments did allow contact with a single horse, however roaming was restricted or prevented and fGC concentrations were numerically higher (although not significantly so) than the group housed treatment. Significantly higher fGC concentration, significantly reduced compliance and one incidence of stereotypical behaviour were observed in the SHNC treatment. This could suggest that the ability to perform natural behaviour (roaming and social contact) is imperative for the horse and restriction could have a considerable impact on equine wellbeing. These results could also suggest that the optimum housing design must include both the opportunity to display natural behaviour in addition to physical contact with ideally more than one horse. However if this is not possible then visual contact appears to reduce the aversiveness associated with isolated housing.

\subsection{Conclusion}

Inadequate housing design could potentially cause stress and result in negative consequences on the health and wellbeing of domestic horses however, it is one aspect of equine husbandry that could easily be altered. Group housing provides horses with an environment where they are able to display natural behaviour and allows contact with conspecifics improving overall welfare. The behavioural and physiological findings during this study imply that the social housing designs were less aversive than the single housing and provided an improved standard of equine welfare. 


\section{Acknowledgments}

The Authors would like to thank staff and students at the Brackenhurst Equestrian Centre, Nottingham Trent University for their support during this study. Thank you to Beth Woodhouse for collecting and managing the behavioural video footage. Thank you to the North of England Zoological Society, Chester Zoo for the analysis of equine faeces for corticosterone.

\section{References}

Benhajali, H., Richard-Yris, M.A., Leroux, M., Ezzaouia, M., Charfi, F., Hausberger, M., 2008. A note on the time budget and social behaviour of densely housed horses, a case study in Arab breeding mares. Appl Anim Behav Sci, 112, 196-200.

Berger, A., Scheibe, K.M., Michaelis, S., Streich, W.J., 2003. Evaluation of living conditions of free-ranging animals by automated chronobiological analysis of behaviour. Behav Resh Methods, Instruments and Computers, 35(3), 458-466.

Boyd, L., 1988. Time budgets of adult Przewalski horses; effects of sex, reproductive status and enclosure. Applied Anim Behavr Sci. 21, 19-39.

Christensen, J.W., Ladewig, J., Sondergaard, E., Malmkvist, J., 2002. Effects of individual verses group stabling on social behaviour in domestic stallions. Appl Anim Behav Sci, 75, 233 - 248.

Clark, F.E., Fitzpatrik, M., Hartley, A., King, A.J., Lee, T., Routh, A., Walker, S.L., George, K. 2011. Relationship between behaviour, adrenal activity and environment in zoo housed western lowland gorillas (Gorilla gorilla gorilla). Zoo Biology.30, 1-16.

Cooke, S.J., O'Connor,C.M, 2010. Making conservat6ion physiology relevant to policy makers and conservation practitioners. Conservation. Lett. 3, 159-166.

Cooper, J.J., McDonald, L. and Mills, D.S., 2000. The effect of increasing visual horizons on stereotypic weaving: implications for the social housing of stabled horses. Appl Anim Behav Sci, 69, 67-83.

Crowell-Davis, S.L. (1994) Daytime rest behavior of the Welsh pony (Equus caballus) mare and foal. Appl Anim Behav Sci. 40, 197-210.

Duncan, P., 1980. Time-Budgets of Camargue Horses: II. Time-Budgets of Adult Horses and Weaned Sub-Adults. Behaviour. 72(1/2), 26-49.

Duncan, P. (1985) Time-budgets of Camargue horses. III. Environmental influences. Behaviour. 92, 186-208.

Feh, C., de Mazières, J. 1993. Grooming at a preferred site reduces heart rate in horses. Animal Behaviour 46: 1191-1194.

Goodwin, D., 1999. The importance of ethology in understanding the behaviour of the horse. Eq Vet J. Supplement 28, 15-19. 
Green, N.F., Green, H.D., 1977. The wild horse population of Stone Cabin valley, Nevada: A preliminary report. Proceedings of the National Wild Horse Forum. 1, 59-65. Reno; Cooperative Extension Service, University of Nevada.

Heitor, F., do Mar Oom, M. and Vicente, L. (2006) Social relationships in a herd of Sorraia horses Part I. Correlates of social dominance and contexts of aggression. Behavioural Processes. 73, 170-177.

Heleski, C.R., Shelle, A.C., Nielson, B.D., Zanella, A.J., 2002. Influence of housing on weanling horse behaviour and subsequent welfare. Appl Anim Behav Sci, 78, 291-302.

Henderson, J. V. and Waran, N. K. 2001. Reducing equine stereotypies using an equiball. Anim Welf, 10, 73-80.

Jørgensen, G.H.M., Linn Borsheim, L., Mejdell, C.M., Søndergaard, E. and Bøe, K.E., 2009. Grouping horses according to gender - effects on aggression, spacing and injuries. Appl Anim Behav Sci, 120, 94-99.

Keay, J.M., Singh, J., Gaunt, M.C., Kaur, T. 2006 Fecal glucocorticoids and their metabolites as indicators of stress in various mammalian species: a literature review. $J$. of Zoo Wildlife Medicine. 37, 234-244.

Mason, G.J., 1991. Stereotypy: a critical review. Anim Behav, 41, 1015-1038.

Mayes, E., Duncan, P., 1986. Temporal patterns of feeding behaviour in free-ranging horses. Behaviour. 96, 105-129.

McBride, S.D., Cuddelford, D., 2001. The putative welfare reducing effects of preventing equine stereotypic behaviour. Anim Welf, 10, 173-189.

McDonnell, S.M. and Poulin, A. (2002) Equid play ethogram. Appl AnimBehav Sci. 78, 263-290.

McGreevy, P.D., Cripps, P.J., French, N.P. Green, L.E. and Nicol, C.J., 1995. Management factors associated with stereotypic and redirected behaviour in the thoroughbred horse. Eq Vet. J. 27(2), 86-91.

Munro, C.J, Stabenfeldt, G.H. 1984 Development of a microtitre plate enzyme immunoassay for the determination of progesterone. J. of Endocrinology. 101, 41-49.

Nakayama, K., Got, S., Karaoke, K., Nakamura, K. 2005. Decrease in nasal temperature of rhesus monkeys (Macaca mulatto) in negative emotional state. Physiol and behav, 84(5), 783-790.

Rivera, E., Benjamin, S., Nielson, B., Zanella, A.J., 2002. Behavioural and physiological responses of horses to initial training; the comparison between pastured versus stalled horses. Appl Anim Behav Sci, 78, 235-252.

Sapolsky, R.M., Romero, L.M., Munck, A.U., 2000. How Do Glucocorticoids Influence Stress Responses? Integrating Permissive, Suppressive, Stimulatory, and Preparative Actions. Endocrine Reviews, 21(1), 55-89.

Sondergaard, E., Ladewig. J., 2004. Group housing exerts a positive effect on the behaviour of young horses during training. Appl AnimBehav Sci, 87(1-2). 105-118. 
Stewart, M., Stafford, K.J., Dowling, S.K., Schaefer, A.L., Webster, J.R., 2008 Eye temperature and heart rate variability of calves disbudded with or without local anaesthetic. Physiol and behav, 93, 789-797.

Touma, C., Palme, R. 2005. Measuring fecal glucocorticoid metabolites in mammals and birds: the importance of validation. Ann.N.Y. Academy Sci. 1046, 54-74.

Uden, P., Rounsaville, G.R., Wiggans, G.R., and Van Soest, P.J. 1982 The measurement of liquid and solid digesta retention in ruminants, equines and rabbits given timothy hay. Br. J. Nutr. 48: 329-339

Veasy, J.S., Waran, N.K., Young, R.J., 1996. On Comparing the behaviour of zoo housed animals with wild conspecifics as a welfare indicator, using the giraffe (Glraffa Camelopardalis) as a model. Anim welf, 5(2), 139-153.

Visser, E, K., Ellis, A.D, Van Reenen, C.G., 2008. The effect of two different housing conditions on the welfare of young horses stabled for the first time. Appl Anim Behav Sci, 114, (3-4), 521-533.

Walker, S.L., Waddell, W.T., Goodrowe, K.L. 2002 Reproductive endocrine patterns in captive female and male red wolves (Canis rufus) assessed by fecal and serum hormone analysis. Zoo Biology. 21(4) 321-335

Watson, R., Munro, C.J., Edwards, K.L., Norton, V., Brown, J.L., Walker, S.L. 2013 Development of a versatile enzyme immunoassay for non-invasiveassessment of glucocorticoid metabolites in a diversity of taxonomic species. Gen Comp Endocrinol 186: 16-24.

Winskill, L.C., Waran, N.K., Channing, C., Young, R.J., 1995. Stereotypies in the stabled horse; Causes, treatment and prevention. Current Science, 69, 310-316.

Yarnell, K., Hall., Billett, E., 2013 An assessment of the aversive nature of an animal management procedure (clipping) using behavioural and physiological measures. Physiol and Behav. 118, 32-39. 